\title{
Evidence-based support for the use of proton pump inhibitors in cancer therapy
}

\author{
Stefano Fais ${ }^{*}$
}

\begin{abstract}
'We can only cure what we can understand first', said Otto H. Warburg, the 1931 Nobel laureate for his discovery on tumor metabolism. Unfortunately, we still don't know too much the mechanisms underlying of cancer development and progression. One of the unsolved mystery includes the strategies that cancer cells adopt to cope with an adverse microenvironment. However, we knew, from the Warburg's discovery, that through their metabolism based on sugar fermentation, cancer cells acidify their microenvironment and this progressive acidification induces a selective pressure, leading to development of very malignant cells entirely armed to survive in the hostile microenvironment generated by their own metabolism. One of the most mechanism to survive to the acidic tumor microenvironment are proton exchangers not allowing intracellular acidification through a continuous elimination of $\mathrm{H}^{+}$either outside the cells or within the internal vacuoles. This article wants to comment a translational process through which from the preclinical demonstration that a class of proton pump inhibitors (PPI) exploited worldwide for peptic ulcer treatment and gastroprotection are indeed chemosensitizers as well, we have got to the clinical proof of concept that PPI may well be included in new anti-cancer strategies, and with a solid background and rationale.
\end{abstract}

\section{Introduction}

While the research in cancer with the purpose of discovering new more effective and less toxic therapies is burning, fuelled by excellent ideas, it is at least astonishing to read what is published in recent report by Globocan. This document has teached us that in 2012 approximately 32.6 million people were living with cancer (within 5 years of diagnosis), 14.1 million were adults newly diagnosed and 8.2 million of these cancer patients died. (Globocan, http://globocan.iarc.fr/Pages/fact_sheets_cancer.aspx) [1]. These data should oblige us to think that there is a urgent need for strategies that will help the humanity to face off in short time with this very aggressive problem; with the aim of both preventing and treating cancer with safe and effective new treatments resulting in durable disease remission and increased overall survival. The most recent approaches in the war against cancer were based on the success of antibiotics that was inspired by the magic bullets' Paul Ehrlich's principle, introduced

\footnotetext{
*Correspondence: stefano.fais@iss.it

Department of Therapeutic Research and Medicines Evaluation, National Institute of Health (Istituto Superiore di Sanità), Viale Regina Elena 299,
} 00161 Rome, Italy more than 100 years ago. The successful use of antibiotics against infectious agents supported the use of the same approach against malignant tumours: to set up new drugs that selectively target and kill tumour cells [2]. After so many years we are still waiting for the magic bullet against malignant tumours. New approaches are now being proposed, such as developing therapeutic strategies aimed at controlling cancer rather than trying to cure it [3]. However, it is also possible to approach new anticancer therapies by trying to understand the mechanisms through which cancer cells avoid growth control. It is possible that cancers also use the same mechanisms to overcome the cytotoxic effect of chemotherapeutic agents, which very often induce more adverse side effects than real benefits. Moreover, despite the use of multiple drug combination protocols and the development of novel targeted anticancer strategies, chemoresistance remains a big problem in cancer treatment [4]. Further understanding on the "life style" of malignant tumours is required. Tumor metabolism and microenvironmental acidity are both involved in tumor resistance to therapies and in allowing growth and progression against a poorly armed body reaction. One of the best defined cascade of 
events occurring into the tumor microenvironment is the so called "Warburg effect" [5], as represented by an aberrant metabolic pathway of tumors, initially triggered by the hypoxic conditions that selects cells able to survive at low oxygen levels by fermentating sugars and releasing lactate, thus leading to extracellular acidification [6]. Within the tumor mass the rapid turnover of aberrantly dividing cancer cells, implying peculiar glucose utilization, amino acid metabolism and ATP hydrolysis, leads to production and release of large amounts of protons into the extracellular compartment, [7-10]. One intriguing hypothesis is that the highly competitive microenvironment, secondary to tumor proliferation and metabolism, selects the cells best adapted to survive in these hostile conditions. Uncontrolled tumor cell proliferation, acid production (secondary to tumor metabolism) and tissue hypoxia (secondary to low blood supply), all contribute to generate a highly hostile tumor microenvironment with conditions that are unsuitable for most cells. In order to thrive in such an unfavorable microenvironment, tumor cells must develop systems to actively extrude excess protons $[9,11]$. These mechanisms include V-ATPase, $\mathrm{Na}^{+} / \mathrm{H}^{+}$exchanger (NHE), monocarboxylate transporters (MCTs) and carbonic anhydrase 9 [9]. We have performed a series of pre-clinical and clinical studies highly supporting the use of a class of proton pump inhibitors (PPI) currently used for the treatment of peptic disease and as gastroprotectors, and including omeprazole, esomeprazole, lansoprazole, pantoprazole and rabeprazole, in the treatment of cancer patients as well $[12,13]$. This commentary will introduce the readers to this discovery in cancer research from the pre-clinical studies [14-18] to the four clinical studies performed in either human $[19,20]$ and domestic animal $[21,22]$ patients.

\section{The novelty and the future}

The peculiar anaerobic or aerobic metabolism of glucose by cancer cells leads to the accumulation of acid byproducts resulting in an acid milieu that strongly affects tumor cells and their host [7, 8, 23, 24] Low extracellular/intratumoral $\mathrm{pH}$ is a major cause of tumor unresponsiveness to the vast majority of cytotoxic drugs, mostly because the $\mathrm{H}^{+}$rich tumor microenvironment leads to protonation of the chemotherapeutic agent causing both its neutralization outside the cells and prevention of reaching its intracellular targets [7, 8, 23, 24]. The prime cause of tumor microenvironment acidification is secondary to the byproducts of tumor metabolism, namely protons, coupled with reduced perfusion. However, this condition progressively selects cells adapted to survive in the acidic extracellular tumor microenvironment, which is due to overexpression and activation of membrane-bound $\mathrm{pH}$-regulating systems that contribute to prevent intracellular acidification. Among them, vacuolar-type $\mathrm{H}^{+}$ATPases seem to be involved in the acidification of tumor microenvironment [9, $23,24]$. Vacuolar $\mathrm{H}^{+}$ATPase (V-ATPase) is a complex multisubunit protein devoted to the transport of protons from the cytoplasm towards intracellular compartments and from inside to outside of the cell through the cytoplasmic membrane [10]. V-ATPases are made of a transmembrane subunit, named V0 complex, devoted to proton transfer and a cytoplasmic portion, named V1 complex, that provides the necessary energy for proton translocation [25]. Because of its role in the regulation of cellular pH homeostasis, V-ATPase is involved in multiple cellular functions including endocytosis and activation of proteases [25], angiogenesis [26], autophagy [27] and amino acids sensing via interaction with mTOR [28]. Tumor cells located at the margin of neoplastic masses are often away from newly formed blood vessels, receiving and inadequate supply of oxygen and nutrients. Such cells survive and adapt to a highly selective environment characterized by hypoxic and acidic conditions caused by increased glycolysis and reduced tissue perfusion [29]. Augmented expression of V-ATPase is considered to be a well-designed compensatory mechanism that in fact confers survival and growth advantages to cancer cells [29-33]. Among its activities, V-ATPase contributes to lower extracellular $\mathrm{pH}$ ( $\mathrm{pHe}$ ) thus activating extracellular metalloproteinases that promote tumor cell survival, motility and invasion, resulting in enhanced malignancy ability. There is a bulk of evidence that points out the role of V-ATPase in tumor invasion and multidrug resistance in breast cancer [34-37], oral squamous cell carcinoma [38-40], esophageal carcinoma [41], hepatocellular and pancreatic carcinoma [42, 43], lung carcinoma [44], sarcoma [45, 46] and solid tumors in general [47]. Consequently, inhibition of V-ATPase has become a fascinating and promising strategy to counteract proton metabolism in cancer, which has been investigated in vitro and in vivo, in both preclinical and clinical settings.

From the first preclinical evidences showing that PPI may work either as chemosensitizing agent [14, 17] or highly cytotoxic anti-tumor agents $[15,16,18]$, to the clinical evidences that PPI chemosensitize either human $[19,20]$ or pets tumor patients $[21,22]$, the proof of principle is becoming solid and convincing. PPI were able to chemosensitize human tumor cells of different histologies, through a normalization of extracellular $\mathrm{pH}$, both in vitro and in vivo [14-17]. Actually, one common feature of tumors is that they are acidic $[7,8]$ and the way tumors become acidic is not entirely made clear. However, an interesting hypothesis is that during the primary tumor growth malignant cells develop what is also called 
"Warburg Effect", that is the ability of cancer cells to fermentate sugars with lactate production, independently on the oxygen levels within the tumor mass $[5,6]$. The condition of $\mathrm{H}^{+}$accumulation within the tumor tissues progressively selects tumor cells armed to survive in this hostile microenvironment [8]. One of the most recognized mechanism allowing cancer cells to survive in the acidic milieu are a series of proton exchangers [9], that help the tumors cells in avoiding intracellular acidification. Between these exchangers there are some proton pumps, such as vacuolar ATPases, that are extremely active in tumor cells by pumping $\mathrm{H}^{+}$both from the cytosol to internal vacuoles and from the plasma membrane to the extracellular microenvironment $[9,10]$. Thus, the first idea was to inhibit V-ATPases in order to deprive cancer cells of this mechanism, but direct inhibition of these proton pumps was toxic, being V-ATPases ubiquitary into the body $[10,25]$. We focused our attention on a family of proton pump inhibitors (PPI) that are used worldwide as very potent antiacidic drugs against peptic diseases or as gastro-protectors (i.e. omeprazole, esomeprazole, lansoprazole, pantoprazole and rabeprazole) [48], that did not show relevant systemic toxicity, even in prolonged treatments and at very high dosages, as in patients with Zollinger and Hellison syndrome, but also in other disease conditions [49]. PPI specifically target gastric $\mathrm{H}^{+} / \mathrm{K}^{+}$ATPases, but VATPases as well $[9,10,48]$. PPI are prodrugs needing protonation in acidic milieu to be transformed into the active molecule, while chemical drugs are mostly weak bases, undergoing neutralization outside the tumor cells by protonation [50]. Thus, while acidity represents a potent mechanism of tumor resistance to drugs, PPI exploit tumor acidity to become functional [50-52].We thus started with a series of preclinical investigations showing that PPI sensitize tumor cells and tumors to the action of chemotherapeutics [14, 17]. However, we also showed that PPI per se exert a potent antitumor activity, through an in vivo modulation of tumor $\mathrm{pH}[15,16]$. Lastly we showed that acidity represents a potent mechanism of tumor immune escape and PPI increase the immune reaction against tumors [53]. These preclinical data represented the background for a series of clinical studies aimed at supporting the use of PPI as chemosensitizers. Up to now the results of two clinical trials in humans are published in either osteosarcomas or metastatic breast cancer patients (MBC) $[19,20]$. The results showed that pre-treatment with PPI increased the effectiveness of neoadjuvant chemotherapy in osteosarcoma patients, particularly in the chondroblastic variant [19] and the time to progression (TTP) or overall survival (OS) in MBC patients maintained under PPI treatment for one year after the stop of chemotherapy [20]. Moreover, two clinical studies in companion animals with spontaneous tumors, highly supported the efficacy of PPI in increasing the efficacy of standard chemotherapy and significantly improving the quality of life of treated pets, in either standard treatment [21] or metronomic regimens [22]. More recently, a metanalysis in head and neck tumor patients confirmed an increased response in patients receiving antiacidic drugs, particularly those treated with PPI [54].

\section{Conclusions}

These results should induce to sit down and think to new anti-tumor strategies in which PPI should be included, and highly support some commentaries and reviews published in JTM proposing inhibitors of ion and proton exchangers as a new anti-cancer approach [13, 55]. One open question might be: "How this approach may be accepted being based on a feature that is common to virtually all cancers, when the mainstream approach of research is to set up new therapies that should distinguish between cancer and cancer patients". With this commentary we would like to propose that cancers have much more common features than peculiar molecular pathways.

\section{Competing interests}

The author declare that he has no competing interests.

Received: 7 October 2015 Accepted: 18 November 2015

Published online: 24 November 2015

\section{References}

1. Torre LA, Bray F, Siegel RL, Ferlay J, Lortet-Tieulent J, Jemal A. Global cancer statistics. 2012. CA Cancer J Clin. 2015;65(2):87-108.

2. Welch DR. Biologic considerations for drug targeting in cancer patients. Cancer Treat Rev. 1987;14:351-8.

3. Gatenby RA. A change of strategy in the war on cancer. Nature. 2009:459:508-9.

4. Wilting $\mathrm{RH}$, Dannenberg JH. Epigenetic mechanisms in tumorigenesis, tumor cell heterogeneity and drug resistance. Drug Resist Updat. 2012;2012(15):21-38.

5. Warburg 0. On the origin of cancer cells. Science. 1956;123(3191):309-14.

6. Chen Z, Lu W, Garcia-Prieto C, Huang P. The Warburg effect and its cancer therapeutic implications. J Bioenerg Biomembr. 2007;39:267-74.

7. Trédan O, Galmarini CM, Patel K, Tannock IF. Drug resistance and the solid tumor microenvironment. J Natl Cancer Inst. 2007;99(19):1441-54.

8. Fais S, Venturi G, Gatenby B. Microenvironmental acidosis in carcinogenesis and metastases: new strategies in prevention and therapy. Cancer Met Rev. 2014:33:1095-108.

9. Spugnini EP, Sonveaux P, Stock C, Perez-Sayans M, De Milito A, Avnet S, Garcìa AG, Harguindey S, Fais S. Proton channels and exchangers in cancer. Biochim Biophys Acta. 2015;1848:2715-26.

10. Fais S, De Milito A, You H, Qin W. Targeting vacuolar $\mathrm{H}^{+}$-ATPases as a new strategy against cancer. Cancer Res. 2007;67(22):10627-30.

11. Izumi $H$, Torigoe $T$, Ishiguchi $H$, Uramoto $H$, Yoshida $Y$, Tanabe $M$, Ise T, Murakami T, Yoshida T, Nomoto M, Kohno K. Cellular pH regulators: potentially promising molecular targets for cancer chemotherapy. Cancer Treat Rev. 2003;29:541-9. 
12. Taylor S, Spugnini EP, Assaraf YG, Azzarito T, Rauch C, Fais S. Microenvironment acidity as a major determinant of tumor chemoresistance: proton pump inhibitors (PPIs) as a novel therapeutic approach. Drug Resist Updat. 2015. doi:10.1016/j.drup.2015.08.004.

13. Huber V, De Milito A, Harguindey S, et al. Proton dynamics in cancer. J Transl Med. 2010;8:57

14. Luciani F, Spada M, De Milito A, Molinari A, Rivoltini L, Montinaro A, Marra M, Lugini L, Logozzi M, Lozupone F, Federici C, lessi E, Parmiani G, Arancia G, Belardelli F, Fais S. Effect of proton pump inhibitor pretreatment on resistance of solid tumors to cytotoxic drugs. J Natl Cancer Inst. 2004;96:1702-13.

15. De Milito A, lessi E, Logozzi M, Lozupone F, Spada M, Marino ML, Federici C, Perdicchio M, Matarrese P, Lugini L, Nilsson A, Fais S. Proton pump inhibitors induce apoptosis of human B-cell tumors through a caspaseindependent mechanism involving reactive oxygen species. Cancer Res. 2007;67:5408-17

16. De Milito A, Canese R, Marino ML, Borghi M, lero M, Villa A, Venturi G, Lozupone F, lessi E, Logozzi M, Della Mina P, Santinami M, Rodolfo M, Podo F, Rivoltini L, Fais S. pH-dependent antitumor activity of proton pump inhibitors against human melanoma is mediated by inhibition of tumor acidity. Int J Cancer. 2010;127:207-19.

17. Azzarito T, Venturi G, Cesolini A, Fais S. Lansoprazole induces sensitivity to suboptimal doses of paclitaxel in human melanoma. Cancer Lett. 2015;356:697-703.

18. Lugini L, Federici C, Borghi M, Azzarito T, Marino ML, Cesolini A, Spugnini $E P$, Fais S. Proton pump inhibitors while belonging to the same family of generic drugs show different anti-tumor effect. J Enzyme Inhib Med Chem. 2015;28:1-8.

19. Ferrari S, Perut F, Fagioli F, Brach Del Prever A, Meazza C, Parafioriti A, Picci P, Gambarotti M, Avnet S, Baldini N, Fais S. Proton pump inhibitor chemosensitization in human osteosarcoma: from the bench to the patients' bed. J Transl Med. 2013;11:268.

20. Wang BY, Zhang J, Wang JL, Sun S, Wang ZH, Wang LP, Zhang QL, Lv FF, Cao EY, Shao ZM, Fais S, Hu XC. Intermittent high dose proton pump inhibitor enhances the antitumor effects of chemotherapy in metastatic breast cancer. J Exp Clin Cancer Res. 2015;34(1):85. doi:10.1186/ s13046-015-0194-x

21. Spugnini EP, Baldi A, Buglioni S, Carocci F, de Bazzichini GM, Betti G, Pantaleo I, Menicagli F, Citro G, Fais S. Lansoprazole as a rescue agent in chemoresistant tumors: a phase I/II study in companion animals with spontaneously occurring tumors. J Transl Med. 2011;9:221.

22. Spugnini EP, Buglioni S, Carocci F, Francesco M, Vincenzi B, Fanciulli M, Fais S. High dose lansoprazole combined with metronomic chemotherapy: a phase I/II study in companion animals with spontaneously occurring tumors. J Transl Med. 2014;12:225.

23. Barar J, Omidi Y. Dysregulated $\mathrm{pH}$ in tumor microenvironment checkmates cancer therapy. Bioimpacts. 2013;3:149-62.

24. Daniel C, Bell C, Burton C, Harguindey S, Reshkin SJ, Rauch C. The role of proton dynamics in the development and maintenance of multidrug resistance in cancer. Biochim Biophys Acta. 2013;1832:606-17.

25. Forgac M. Vacuolar ATPases: rotary proton pumps in physiology and pathophysiology. Nat Rev Mol Cell Biol. 2007;8(11):917-29.

26. Rath S, Liebl J, Fürst R, Vollmar AM, Zahler S. Regulation of endothelial signaling and migration by v-ATPase. Angiogenesis. 2014;17(3):587-601. doi:10.1007/s10456-013-9408.

27. Mijaljica D, Prescott M, Devenish RJ. V-ATPase engagement in autophagic processes. Autophagy. 2011;7(6):666-8

28. Zoncu R, Bar-Peled L, Efeyan A, Wang S, Sancak Y, Sabatini DM. mTORC1 senses lysosomal amino acids through an inside-out mechanism that requires the vacuolar $\mathrm{H}^{(+)}$-ATPase. Science. 2011;334(6056):678-83.

29. von Schwarzenberg K, Wiedmann RM, Oak P, Schulz S, Zischka H, Wanner $\mathrm{G}$, et al. Mode of cell death induction by pharmacological vacuolar $\mathrm{H}^{+}$ATPase (V-ATPase) inhibition. J Biol Chem. 2013;288(2):1385-96.

30. Schempp CM, von Schwarzenberg K, Schreiner L, Kubisch R, Muller R, Wagner $\mathrm{E}$, et al. V-ATPase inhibition regulates anoikis resistance and metastasis of cancer cells. Mol Cancer Ther. 2014;13(4):926-37.

31. Sennoune SR, Bakunts K, Martinez GM, Chua-Tuan JL, Kebir Y, Attaya $M N$, et al. Vacuolar $\mathrm{H}^{+}$-ATPase in human breast cancer cells with distinct metastatic potential: distribution and functional activity. Am J Physiol Cell Physiol. 2004;286(6):C1443-52.
32. Martinez-Zaguilan R, Raghunand N, Lynch RM, Bellamy W, Martinez GM, Rojas $\mathrm{B}$, et al. pH and drug resistance. I. Functional expression of plasmalemmal $\mathrm{V}$-type $\mathrm{H}^{+}$-ATPase in drug-resistant human breast carcinoma cell lines. Biochem Pharmacol. 1999;57(9):1037-46.

33. Raghunand N, Martinez-Zaguilan R, Wright SH, Gillies RJ. pH and drug resistance. II. Turnover of acidic vesicles and resistance to weakly basic chemotherapeutic drugs. Biochem Pharmacol. 1999;57(9):1047-58.

34. Feng S, Cai M, Liu P, Wei L, Wang J, Qi J, et al. Atp6v1c1 may regulate filament actin arrangement in breast cancer cells. PLoS One. 2014;9(1):e84833

35. Feng S, Zhu G, McConnell M, Deng L, Zhao Q, Wu M, et al. Silencing of atp6v1 1 prevents breast cancer growth and bone metastasis. Int J Biol Sci. 2013;9(8):853-62.

36. von Schwarzenberg K, Lajtos T, Simon L, Muller R, Vereb G, Vollmar AM. $\checkmark$-ATPase inhibition overcomes trastuzumab resistance in breast cancer. Mol Oncol. 2014;8(1):9-19.

37. You H, Jin J, Shu H, Yu B, De Milito A, Lozupone F, et al. Small interfering RNA targeting the subunit ATP6L of proton pump V-ATPase overcomes chemoresistance of breast cancer cells. Cancer Lett. 2009;280(1):110-9.

38. Garcia-Garcia A, Perez-Sayans Garcia M, Rodriguez MJ, Antunez-Lopez J, Barros-Angueira F, Somoza-Martin M, et al. Immunohistochemical localization of $\mathrm{C} 1$ subunit of $\mathrm{V}$-ATPase (ATPase $\mathrm{C} 1$ ) in oral squamous cell cancer and normal oral mucosa. Biotech Histochem. 2012;87(2):133-9.

39. Perez-Sayans M, Somoza-Martin JM, Barros-Angueira F, Diz PG, Rey JM, Garcia-Garcia A. Multidrug resistance in oral squamous cell carcinoma: the role of vacuolar ATPases. Cancer Lett. 2010;295(2):135-43.

40. Perez-Sayans M, Reboiras-Lopez MD, Somoza-Martin JM, Barros-Angueira F, Diz PG, Rey JM, et al. Measurement of ATP6V1C1 expression in brush cytology samples as a diagnostic and prognostic marker in oral squamous cell carcinoma. Cancer Biol Ther. 2010;9(12):1057-64.

41. Huang L, Lu Q, Han Y, Li Z, Zhang Z, Li X. ABCG2/N-ATPase was associated with the drug resistance and tumor metastasis of esophageal squamous cancer cells. Diagn Pathol. 2012;7:180.

42. Xu J, Xie R, Liu X, Wen G, Jin H, Yu Z, et al. Expression and functional role of vacuolar $\mathrm{H}^{(+)}$-ATPase in human hepatocellular carcinoma. Carcinogenesis. 2012;33(12):2432-40.

43. Chung C, Mader CC, Schmitz JC, Atladottir J, Fitchev P, Cornwell ML, et al. The vacuolar-ATPase modulates matrix metalloproteinase isoforms in human pancreatic cancer. Lab Invest. 2011;91(5):732-43.

44. Lu Q, Lu S, Huang L, Wang T, Wan Y, Zhou CX, et al. The expression of $\checkmark$-ATPase is associated with drug resistance and pathology of non-smallcell lung cancer. Diagn Pathol. 2013;8:145.

45. Perut F, Avnet S, Fotia C, Baglio SR, Salerno M, Hosogi S, et al. V-ATPase as an effective therapeutic target for sarcomas. Exp Cell Res. 2014;320(1):21-32.

46. Avnet S, Di Pompo G, Lemma S, Salerno M, Perut F, Bonuccelli G, et al. $\checkmark$-ATPase is a candidate therapeutic target for Ewing sarcoma. Biochim Biophys Acta. 2013;1832(8):1105-16.

47. Perez-Sayans M, Garcia-Garcia A, Reboiras-Lopez MD, Gandara-Vila P. Role of V-ATPases in solid tumors: importance of the subunit C (review). Int J Oncol. 2009;34(6):1513-20.

48. Mullin JM, Gabello M, Murray LJ, Farrell CP, Bellows J, Wolov KR, Kearney KR, Rudolph D, Thornton JJ. Proton pump inhibitors: actions and reactions. Drug Discov Today. 2009;14:647-60.

49. Han YM, Hahm KB, Park JM, Hong SP, Kim EH. Paradoxically augmented anti-tumorigenic action of proton pump inhibitor and Gastrinin APCMin/+ intestinal polyposis model. Neoplasia. 2014;16(1):73-83.

50. De Milito A, Fais S. Tumor acidity, chemoresistance and proton pump inhibitors. Future Oncol. 2005;1:779-86.

51. Wojtkowiak JW, Verduzco D, Schramm KJ, Gillies RJ. Drug resistance and cellular adaptation to tumor acidic $\mathrm{pH}$ microenvironment. Mol Pharm. 2011:8:2032-8

52. Gerweck LE, Vijayappa S, Kozin S. Tumor pH controls the in vivo efficacy of weak acid and base chemotherapeutics. Mol Cancer Ther. 2006;5:1275-9.

53. Calcinotto A, Filipazzi P, Grioni M, lero M, De Milito A, Ricupito A, Cova A, Canese R, Jachetti E, Rossetti M, Huber V, Parmiani G, Generoso L, Santinami M, Borghi M, Fais S, Bellone M, Rivoltini L. Modulation of microenvironment acidity reverses anergy in human and murine tumor-infiltrating T lymphocytes. Cancer Res. 2012;72:2746-56. 
54. Papagerakis S, Bellile E, Peterson LA, Pliakas M, Balaskas K, Selman S, Hanauer D, Taylor JM, Duffy S, Wolf G. Proton pump inhibitors and histamine 2 blockers are associated with improved overall survival in patients with head and neck squamous carcinoma. Cancer Prev Res (Phila). 2014;7(12):1258-69.
55. Harguindey S, Arranz JL, Polo Orozco JD, et al. Cariporide and other new and powerful NHE1 inhibitors as potentially selective anticancer drugsan integral molecular/biochemical/metabolic/clinical approach after one hundred years of cancer research. J Transl Med. 2013;11:282.
Submit your next manuscript to BioMed Central and we will help you at every step:

- We accept pre-submission inquiries

- Our selector tool helps you to find the most relevant journal

- We provide round the clock customer support

- Convenient online submission

- Thorough peer review

- Inclusion in PubMed and all major indexing services

- Maximum visibility for your research

Submit your manuscript at www.biomedcentral.com/submit
(OioMed Central 